\title{
Desenvolvimento de um Livro Interativo em Realidade Aumentada para Ensino e Aprendizagem Musical
}

\author{
Ana Grasielle Dionísio Corrêa, Maira Lima, Daniel Gomes de Melo \\ Ivete Irene dos Santos
}

Faculdade de Computação e Informática da Universidade Presbiteriana Mackenzie São Paulo - SP - Brasil

ana.correa@mackenzie.br, maira.limas@hotmail.com, daniel.g.melo@gmail.com, iveteirene@mackenzie.br

\begin{abstract}
Resumo. Este artigo apresenta o desenvolvimento de um Sistema Interativo em Realidade Aumentada para apoio ao processo de iniciação musical infantil. O sistema, denominado MusicandoRA, é composto de um material impresso (livro) e um software para interação com os elementos musicais $3 D$. O MusicandoRA propõe diversas possibilidades para trabalhar nos estágios iniciais de educação musical com crianças e adolescentes de até 15 anos de idade. Avaliações do MusicandoRA foram feitas com alunos e especialistas em Educação Musical e apontam os beneficios que esta ferramenta pode trazer para o ensino e aprendizagem musical nas escolas.
\end{abstract}

Palavras-chaves: sistemas interativos, realidade aumentada, educação musical.

\begin{abstract}
This paper presents a development of Augmented Reality Interactive System to support of children's musical initiation process. The system, called MusicandoRA, consists of printed material (book) and software to interact with musical elements 3D. MusicandoRA proposes several possibilities to work in the early stages of musical education to children and adolescents up to age 15. Reviews MusicandoRA were made with students and experts in music education and the benefits show that this tool can bring to teaching and learning music.
\end{abstract}

Keywords: interactive systems, augmented reality, musical education.

\section{Introdução}

O ensino e aprendizagem podem ser vistos como um processo progressivo que necessita de diferentes abordagens para seu aperfeiçoamento. De acordo com Gaiza (1998), a música e o som, considerados como energia, estimulam o movimento interno e externo do homem, impulsionando-o a ação e promovendo nele uma multiplicidade de condutas de diferentes qualidades e graus. Segundo o autor, em qualquer situação de aprendizagem, sempre haverá características individuais dos alunos que suscitam diferentes estratégias de aprendizado. Neste sentido, devem-se desencadear práticas que contribuam para o desenvolvimento da inteligência e do pensamento crítico como, por exemplo, atividades ligadas à música. 
De acordo com Brito (2003), a música é um poderoso instrumento para beneficiar o sistema educacional, pois, além de promover a autodisciplina, pode estimular, de forma prazerosa, a criatividade e o raciocínio e outros dons (habilidades) e aptidões. Com a educação musical voltando a ser conteúdo obrigatório em todas as escolas do Brasil (Lei $\mathrm{n}^{\mathrm{o}} 11.769$ de 18 de agosto de 2008), surge a necessidade de oferecer programas e materiais de apoio que contribuam com o processo de aprendizagem musical nas escolas.

Motivados pela emergente necessidade da inclusão digital, professores juntamente com pesquisadores, têm procurado realizar estudos envolvendo o uso pedagógico dos computadores e de seus recursos multimídia (Corrêa e Lopes, 2004), (Fagundes et al, 2008), (Schramm, 2009), (Rosas e Behar, 2012). Considera-se, nesse sentido, imprescindível a realização de pesquisas que verifiquem as possibilidades de implementação dos aportes computacionais na educação musical.

A Realidade Aumentada (RA) tem se mostrado uma ferramenta facilitadora e motivadora para trabalhar com crianças em momentos de recreação e também nas salas de aula (Silva e Kirner, 2010), (Andujar et al, 2011), (Reis e Kirner, 2012). Por meio da RA é possível criar interfaces interativas mais atrativas que podem ser manipuladas com as mãos, sem necessidade de uso de periféricos convencionais como teclado e mouse (Richard et al, 2007), (Corrêa et al, 2007). Esta característica da RA pode proporcionar maior interação entre o aluno e o objeto de estudo, despertando o interesse e a curiosidade, havendo assim, maior probabilidade de engajamento por parte do aluno durante as aulas. Além disso, a RA tem trazido novas possibilidades para trabalhar com pessoas com necessidades especiais por possibilitar apresentar através de sons e imagens, ideias abstratas e conceitos de difícil assimilação (Souza e Kirner, 2011), (Corrêa et al, 2011).

Neste contexto, este trabalho vem contribuir com a pesquisa e o desenvolvimento de uma aplicação de RA voltada para apoiar o processo de ensino e aprendizagem musical. Trata-se de um livro acompanhado de um software para iniciação musical, denominado MusicandoRA, incrementado com características de RA capazes de potencializar os sentidos (visão e audição), além de apresentar um novo conceito em aprendizagem musical com a utilização da tecnologia $\mathrm{O}$ material musical dispõe de páginas compostas de conteúdos musicais (textos e imagens) para aulas de iniciação musical, incrementado com recursos que incluem a visualização $3 \mathrm{D}$ de instrumentos musicais e audição de sons e melodias. No final do livro, são propostos alguns desafios musicais para estimular habilidades cognitivas como atenção, concentração, memorização e raciocínio. A seguir, são apresentados alguns dos conceitos musicais que são abordados no livro MusicandoRA e, em seguida, a Teoria Espiral de Desenvolvimento Musical de Keith Swanwick e June Tillman (1986) que propõe estágios para o ensino da música.

\section{Conceitos Musicais}

O MusicandoRA apresenta conceitos musicais de acordo com abordagens de alguns autores. Para a maioria deles, a música é definida como sendo uma linguagem que combina sons e silêncio no universo (Brito, 2003). Contudo, as características do som não podem ser interpretadas com sendo a própria música. De acordo com Brito (2003), a 
passagem do sonoro ao musical se dá pelo relacionamento entre os parâmetros dos sons e o silêncio. Os parâmetros sonoros são (Brito, 2003):

- Altura: refere-se aos sons médios, graves e agudos. Pode ser representada pelas notas musicais (dó, ré, mi, fá, sol, lá e si) ou altura irregular (barulhos).

- Duração: refere-se ao tempo de prolongamento do som. Na escrita musical é representada pelas figuras musicais (semibreve, mínima, semínima, etc.).

- Intensidade: refere-se à força com que o som é executado, a qual resulta no volume do som.

- Timbre: É a característica que diferencia (personaliza) cada som. É voz do instrumento musical.

Além do som, a música é composta por outros três elementos (Brito, 2003):

- Ritmo: movimento que ocorre em intervalos regulares. É conhecido também como cadência. É possível observar o ritmo no nosso cotidiano como, por exemplo, na batida do coração ou mesmo nos ponteiros do relógio.

- Melodia: execução de sons executada de forma sucessiva

- Harmonia: combinação de sons simultâneos. Consiste na execução de vários sons ao mesmo tempo.

Os instrumentos musicais são divididos em três categorias (Brito, 2003):

- Corda: são aqueles cujos sons são produzidos pela vibração de cordas elásticas esticadas sobre uma caixa de ressonância como, por exemplo, violão e guitarra.

- Sopro: são aqueles cujo som é produzido pela vibração de uma massa de ar originada no instrumento como, por exemplo, flauta e saxofone.

- Percussão: são aqueles cujo som é produzido pelo próprio corpo do instrumento, como no caso do reco-reco e triângulo ou, através de membranas esticadas sobre uma caixa de amplificação como, por exemplo, caixa e tambor.

\subsection{Modelo Espiral de Desenvolvimento Musical}

Swanwick e Tillman (1986) desenvolveram uma teoria conhecida como Modelo Espiral de Desenvolvimento Musical. Este modelo propõe estágios de desenvolvimento musical que contempla os elementos comuns a toda a experiência musical significativa:

- Material: aplica-se a crianças de até os 04 anos de idade, sendo caracterizada pela experimentação dos sons dos ambientes a sua volta. Pode ocorrer de forma sensorial, com exploração sensorial das qualidades sonoras ou de forma manipulativa, onde é possível observar um controle manipulativo sobre os sons.

- Expressivo: aplica-se a crianças de 05 a 09 anos de idade, sendo caracterizada pela manipulação dos instrumentos musicais, originando as primeiras composições, parecidas com os sons que a criança está acostumada a ouvir e cantar. Pode ocorrer de forma pessoal, a partir do controle dos sons ou, de forma vernacular, onde ocorre uma adequação a convenções musicais estereotipadas.

- Forma: aplica-se a crianças de 10 aos 15 anos de idade, sendo caracterizada pelo respeito criado por alguns estilos musicais específicos, tendo como objetivo 
estabelecer conexões com outras crianças e/ou jovens, como o pop ou rock. Pode ocorrer de forma especulativa, com respostas intuitivas à forma, sendo notável uma imaginação "brincalhona", com surpresas e expectativas ou, de forma idiomática, em que a imaginação ocorre dentro de estilos conhecidos.

- Valor: aplica-se aos indivíduos a partir dos 15 anos de idade, onde a música passa a representar um valor importante para o indivíduo, mais por relação emocional que por modismos ou um consenso social. Pode ocorrer de forma simbólica, onde há um comprometimento pessoal com o valor simbólico da música ou, de forma sistemática, através de possibilidades de discurso musical.

Dessa forma, o Modelo Espiral contribui para o delineamento de critérios bem fundamentados para avaliar uma produção musical. A partir destes critérios, o professor pode conduzir seus alunos em atividades que propiciem e revelem uma compreensão musical cada vez mais profunda.

\section{Concepção do MusicandoRA}

O MusicandoRA é composto de um material impresso (livro) e um software para interação com os elementos musicais 3D. Propõe diversas possibilidades para trabalhar nos estágios iniciais do modelo Espiral de Desenvolvimento Musical.

O material impresso, composto de textos e imagens, foi baseado no conteúdo musical publicado por Brito (2003). O software foi concebido com tecnologia de Realidade Aumentada e, portanto, é necessário dispor de uma webcam para seu funcionamento. Inicialmente, o usuário utiliza a webcam para capturar imagens de cartões marcadores disponíveis no livro. Estes cartões são compostos por símbolos que estão catalogados no banco de dados do software. Os símbolos musicais detectados são analisados e interpretados pelo software. A interpretação dos símbolos produz objetos virtuais em 3D que são combinados com o mundo real do usuário. O mundo misturado é enviado pelo software para um dispositivo de visualização (tela do computador).

Para implementação do software foi utilizada a linguagem de programação ActionScript 3.0 (AS3) no ambiente de desenvolvimento Adobe Flash CS5. Para executar o software MusicandoRA, o usuário deve instalar no navegador o Flash Player (versão 10 ou superior) e permitir o acesso do plugin à webcam. Os modelos 3D utilizados seguem o padrão Collaborative Design Activity (COLLADA) e podem ser encontrados na Internet na extensão “.dae”. Foram utilizadas as bibliotecas:

- Papervision 3D (versão 2.0) para aplicar as transformações geométricas (rotação, translação e escala) nos modelos 3D.

- Flartoolkit (versão 2.72) para desenvolvimento das aplicações de RA.

A Figura 1a, mostra a interface da tela principal do software MusicandoRA, onde o usuário é convidado a testar sua webcam e a Figura 1b mostra a janela de vídeo ativa onde o usuário aponta uma página do material impresso do MusicandoRA. 

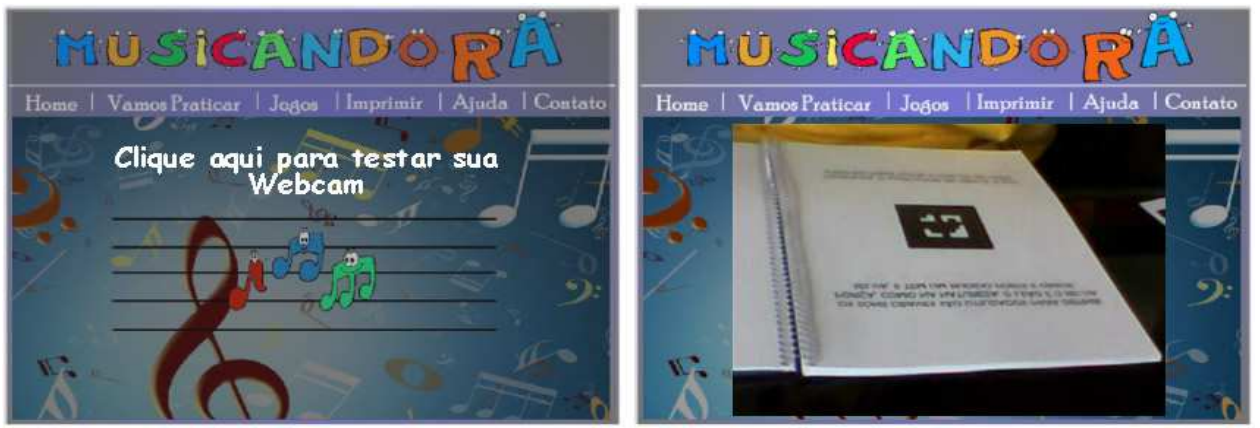

Figura 1 - (a) Tela principal do MusicandoRA; (b) Janela de vídeo ativa;

\subsection{Vamos Praticar}

Instrumentos Musicais: quando o conteúdo tratado no livro MusicandoRA for sobre os instrumentos musicais (sopro, corda ou percussão), ilustrado na Figura 2a, é possível interagir com os cartões que, ao serem inseridos no campo de visão de uma webcam, projetam instrumentos musicais virtuais em 3D (Figura 2b). Ao manipular estes cartões com as mãos, o usuário poderá visualizar estes instrumentos em diferentes perspectivas.
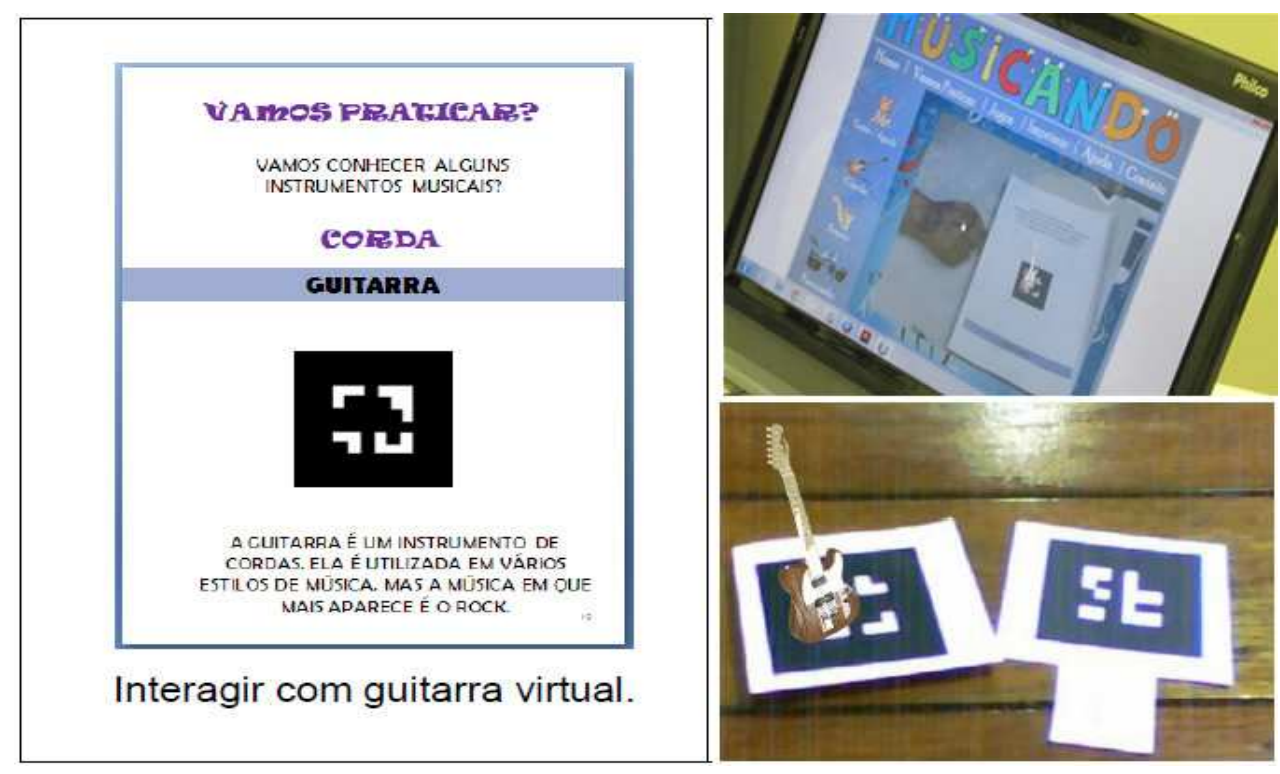

Figura 2 - (a) Página do livro MusicandoRA com conteúdo sobre instrumentos musicais; (b) Tela do software MusicandoRA e Instrumentos musicais em 3D

Notas Musicais: quando o conteúdo tratado no livro MusicandoRA for sobre a altura das notas musicais, é possível interagir com os cartões correspondentes às notas musicais (Figura 3a). Estes cartões geram cubos coloridos que, ao serem obstruídos pelas mãos do usuário, executam os sons das respectivas notas musicais (Figura 3b). 


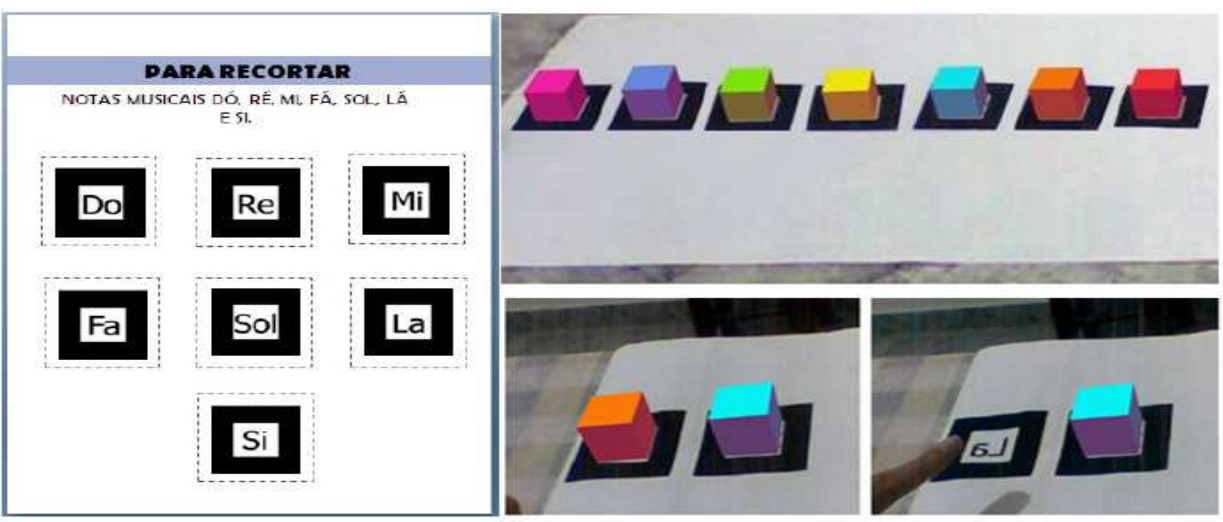

Figura 3 - (a) Página do livro MusicandoRA com os cartões respectivos às notas musicais; (b) Interação com os cubos que representam as notas musicais

As notas musicais são executadas no timbre do piano, mas pode-se alterar este timbre, colocando-se no campo de visão da webcam o cartão do instrumento musical desejado.

Sons Graves e Agudos: ainda nesta categoria "Vamos Praticar", o livro MusicandoRA oferece uma brincadeira que envolve a altura dos sons (grave ou agudo). Para exemplificar um som de altura grave, o usuário posiciona o marcador indicado no campo de visão da webcam e um leão surge rugindo na tela do computador (Figura 4a) para ilustrar os conceitos de sons graves. Da mesma forma, para ouvir um som de altura aguda, um passarinho aparece assobiando na tela do computador (Figura 4b) ilustrando a emissão de sons agudos.
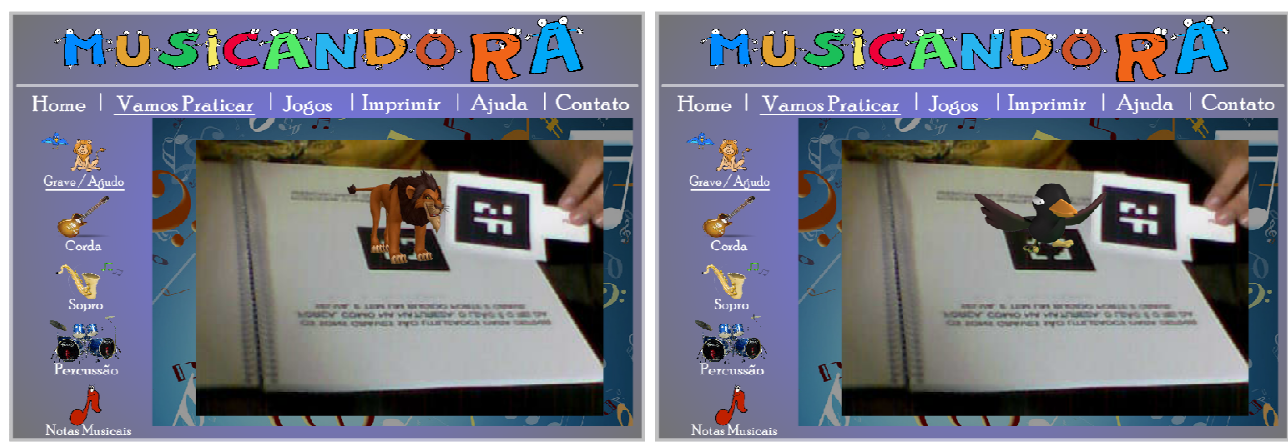

Figura 4 - (a) Modelo 3D do leão representando som grave; (b) Modelo 3D do passarinho representando som agudo

Ativar e Desativar Sons: se algum instrumento musical 3D estiver visível na janela do software e, ao introduzir uma placa de controle (iniciar) no campo de visão da webcam (Figura 5), uma pequena melodia, correspondente ao instrumento musical virtual, é executada. Da mesma forma, caso alguma melodia esteja sendo executada, ao introduzir uma placa de controle (parar) no campo de visão da webcam, a melodia será interrompida pelo sistema. As placas estão disponíveis no final do livro para recortar. 


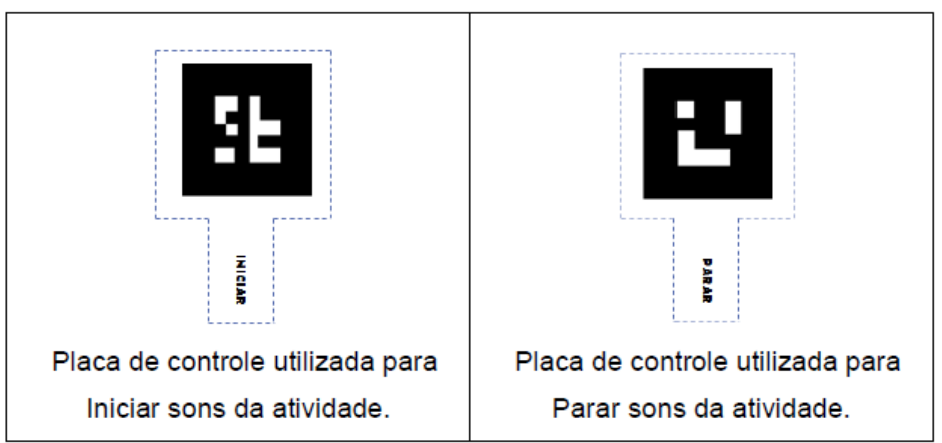

Figura 5 - Placas de Controle dos sons do MusicandoRA

Transportar, Trocar e Copiar Elementos Virtuais: ao introduzir a placa de controle (transporte) no campo de visão da webcam, é possível transportar um elemento virtual de uma página do livro para outra. Do mesmo modo, a placa de controle (troca) possibilita trocar um elemento virtual por outro. A placa de controle (cópia) possibilita acrescentar uma cópia de um determinado elemento virtual nas páginas do livro.

\subsection{Jogos do MusicandoRA}

Adivinhar os Sons dos Instrumentos Musicais: trata-se de um jogo cujo objetivo é identificar qual instrumento musical pertence à determinada melodia que estiver sendo executada. $\mathrm{O}$ sistema carrega as imagens dos instrumentos musicais (figura 6a) e, em seguida, executa um trecho de uma melodia. O usuário então deve fazer a oclusão do instrumento musical correspondente ao timbre da melodia que estiver sendo executada. Se estiver correto, o sistema emite mensagem de acerto na tela do computador e executa um som de aplausos (figura 6b). No caso de erro, o sistema emite mensagem de erro com um efeito sonoro de erro e solicita ao usuário que tente novamente (figura $6 \mathrm{c}$ ).
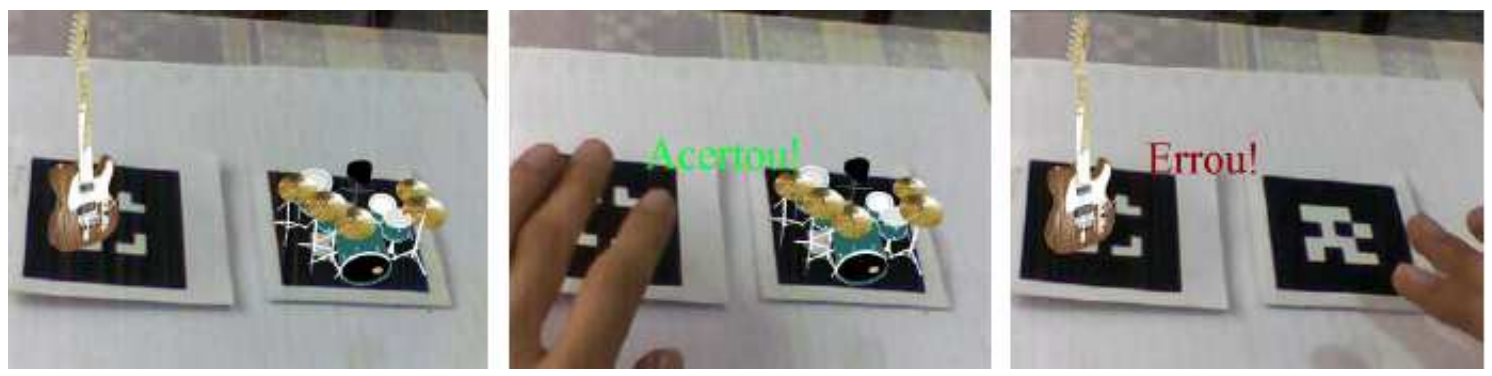

Figura 6 - (a) Instrumentos musicais do jogo; (b) Oclusão do instrumento correto; (c) Oclusão do instrumento errado.

Em outro desafio, aparecem diversos instrumentos musicais diferentes em uma mesma página do livro. O usuário deve ouvir as melodias indicadas pelos cartões marcadores no decorrer da página e, com a pá de transporte, deve escolher o instrumento referente ao timbre da melodia e leva-lo até ela. A Figura 7 mostra alguns instrumentos musicais deste jogo. 

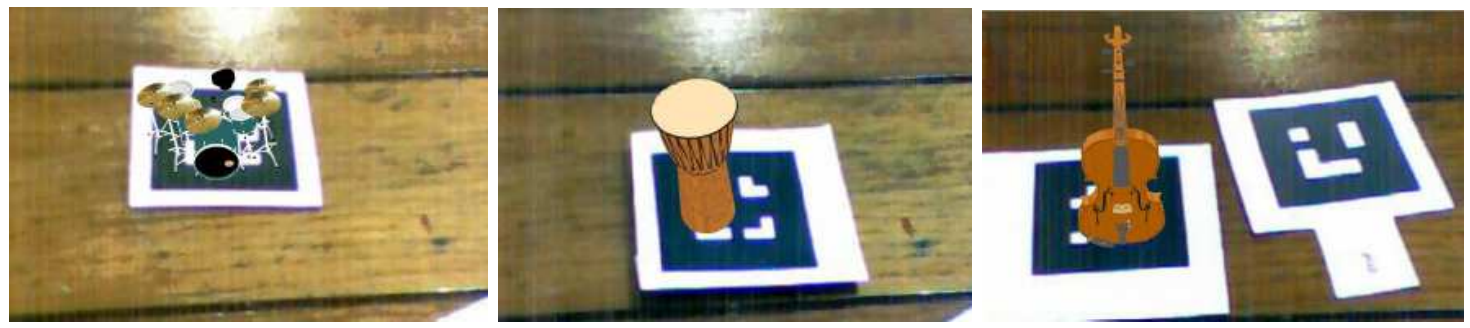

Figura 7 - Instrumentos musicais do jogo dos instrumentos

\section{Resultados Preliminares}

Uma educadora, que leciona há 5 anos, na educação infantil colaborou na etapa de avaliação do sistema MusicandoRA. Foi realizada uma aula piloto, na residência da educadora, no mês de março, com utilização do sistema para a exposição de conteúdos musicais a quatro voluntários entre 7 e 10 anos, já alfabetizados, para verificar a acessibilidade. Os participantes foram observados durante a aula e participaram, na sequência, de uma entrevista.

O sistema MusicandoRA foi montado sobre uma mesa onde foi possível apoiar a webcam e o livro. A educadora utilizou o livro desenvolvido juntamente com o software, para exposição do conteúdo musical para as crianças, procedimentos estes que indicam a possibilidade do uso doméstico do software. Das quatro crianças que fizeram parte dos testes, três têm acesso a computadores em casa. Uma delas, a que teve mais dificuldades para utilizar o programa, não tem acesso a computador em casa, ainda. Acredita-se, levando em consideração o aumento das propostas comerciais e governamentais para a inclusão digital, na possibilidade de acesso, pelo menos no contexto escolar.

O evento ocorreu no período de 1(uma) hora para explicação e aplicação das atividades. No decorrer da aula, foram utilizadas fontes de sons externas ao computador para ampliar o volume dos sons, de forma a facilitar ainda mais assimilação dos conceitos apresentados sobre qualidade do som.

As atividades oferecidas no programa MusicandoRA foram utilizadas como complementares ao conteúdo teórico. A educadora fez uma demonstração inicial do MusicandoRA para que os participantes se tornassem aptos a navegar no sistema e, para reforçar os conceitos musicais apresentados.

Para coleta dos dados, a educadora respondeu a um questionário de satisfação de interação do usuário e, em seguida, foram realizadas entrevistas com os préadolescentes. As questões apresentadas: "Tem Acesso a computadores?", "O programa é interessante (legal)?" "É fácil de usar?", "As atividades durante a aula facilitaram o aprendizado?", "Gostaria que esse método fosse utilizado em sala de aula?", visaram saber a opinião do público-alvo final e são a complementação da pesquisa realizada para a monografia de conclusão de curso.

A partir da interpretação das verbalizações durante o evento e das respostas apresentadas ao questionário, concluiu-se que os usuários consideraram o método de ensino interessante, facilitador do aprendizado dos conceitos apresentados e alegaram gostar de existirem ferramentas educacionais desta natureza diferenciada para apoio de algumas aulas nas escolas regulares. 
Dos Quatro alunos que participaram desta avaliação, apenas um deles não apresentou qualquer dificuldade em utilizar o sistema. Outros dois alunos demonstraram dificuldades apenas na primeira utilização de uma atividade, para interação com os instrumentos musicais, tendo em vista que a manipulação dos marcadores se dá de forma igual entre as atividades, pois não tinham certeza de como os marcadores deveriam ser manipulados, e precisaram do auxílio da educadora. Contudo, depois da prática desta atividade, os alunos conseguiram executar as demais atividades sozinhos, sem a ajuda do educador. O quarto usuário não tinha experiência no uso de computadores e, somente conseguiu utilizar o programa com o auxílio de um colega, porém sem a intervenção de um adulto. Características de exploração e descoberta que o MusicandoRA proporciona aos aprendizes, leva à conclusão de que o sistema pode ser disponibilizado para uso pelos alunos nas escolas e como atividade complementar ou de reforço, em casa. Para estimular mais os alunos e ampliar o conteúdo, a educadora sugeriu:

- Disponibilizar mais tipos de sons no programa, como, por exemplo, mais amostras de sons graves e agudos e amostras de ruídos.

- Diversificar os jogos para que ofereça maiores desafios.

- Criar animações ou vídeos que possibilite aprender a utilizar do programa de forma mais prática e sem a ajuda do educador.

\section{Conclusões}

Este artigo apresentou o MusicandoRA, um livro interativo em Realidade Aumentada para Aprendizagem Musical. Os propósitos do MusicandoRA são: favorecer situações de aprendizagem musical na sala de aula e contribuir com o repositório de tecnologias livres para educação musical através de sua disponibilização na Internet para uso livre.

Dentre os impactos deste trabalho, pode-se destacar: (1) a criação de uma nova forma de manipulação de objetos de aprendizagem voltados ao ensino e aprendizagem musical; (2) a possibilidade de interação com o objeto de aprendizagem musical de forma natural, com as mãos, sem necessidade de uso de dispositivos tecnológicos convencionais como teclado e mouse; (3) a visualização dos objetos de aprendizagem de maneira uniforme, de modo que estes simulem estar em um mesmo local físico.

A realização de testes do protótipo com os usuários é uma metodologia positiva e desejável, pois se pôde receber as orientações pautadas na experiência e no conhecimento técnico dos participantes, validando ou não o produto. O MusicandoRA foi avaliado por especialistas na área da educação musical por meio de testes de interação, juntamente com os pesquisadores, e por meio de um questionário de aplicabilidade e usabilidade. As avaliações com o MusicandoRA permitem concluir que o sistema possibilita a aprendizagem musical e pode ser utilizado individualmente ou coletivamente em casa ou na sala de aula.

Como perspectiva de continuidade deste trabalho, em termos de implementação pretende-se integrar novos desafios musicais e uma estratégia de autoavaliação ao final de cada capítulo do livro. Em termos de avaliação de aplicabilidade, será submetido um plano de pesquisa ao Comitê de Ética em Pesquisa para utilização de avaliações junto aos professores e alunos do ensino regular. 


\section{Referências}

ANDUJAR, J.M.; MEJIAS, A.; Augmented Reality for the Improvement of Remote Laboratories: Na Augmented Remote Laboratory. IEEE Transactions on Education, v. 54, n.3, 2011.

BRITO, Teca de Alencar. Música na Educação Infantil - Propostas para a formação integral da criança. São Paulo: Peirópolis, 2a Edição, 2003.

CONSULARO, L.A.; et al. ARToolKIT: Aspectos Técnicos e Aplicações Educacionais. In: Cardoso, A.; Lamounier E. (Org.). Realidade virtual: uma abordagem prática. São Paulo: Mania de Livro, v. 02, p. 141-183, 2004.

CORRÊA, A.G.D; LOPES, R.D. A Criatividade através da Expressão Musical: Uma Interface Gestual para Composição Musical Interativa. Revista Novas Tecnologias na Educação (RENOTE), v.2, n.2, 2004.

CORRÊA, A.G.D.; et al. GenVirtual: um jogo musical para reabilitação de indivíduos com necessidades especiais. Revista Brasileira de Informática na Educação (RBIE), v. 16, n. 1, p. 10-17, 2008.

FAGUNDES, L.C.; et al. Fluência Digital e Ambientes de Autoria Multimídia. Revista Novas Tecnologias na Educação (RENOTE), v.8, n.3, 2008.

GAINZA, H.V. Estudos de psicopedagogia Musical. São Paulo: Summus, 1988.

REIS, F.M.V.; KIRNER, T.G. Percepção de Estudantes quanto à Usabilidade de um Livro Interativo com Realidade Aumentada para a Aprendizagem de Geometria. Revista Novas Tecnologias na Educação (RENOTE), v.10, n.1, 2012.

RICHARD, E. et al. Augmented reality for rehabilitation of cognitive disabled children: a preliminary study. In: VIRTUAL REHABILITATION, p. 102-108, 2007.

ROSAS, F.W.; BEHAR, P.A. COMPMUS: Um objeto de Aprendizagem para Auxiliar no Desenvolvimento de Competências para o Contexto TecnológicoMusical. Revista Novas Tecnologias na Educação (RENOTE), v.10, n.7, 2012.

SILVA, K.A.C.; KIRNER, C. Vantagens educacionais no uso de jogos em Realidade Aumentada. Revista Novas Tecnologias na Educação (RENOTE), v.2, n.2, 2010.

SOUZA, R.C.; KIRNER, C. Ensino e Aprendizagem de Eletromagnetismo usando Recursos de Realidade Aumentada. Revista Novas Tecnologias na Educação (RENOTE), v.9, n.1, 2011.

SWANWICK, K.; TILLMAN, J. The sequence of musical development: a study of children's composition. British Journal of Music Education, v. 3, p.305-339, 1986.

SCHRAMM, R. Tecnologias aplicadas à Educação Musical. Revista Novas Tecnologias na Educação (RENOTE), v.7, n.2, 2009. 